\title{
En los caminos de la Justicia Transicional en Colombia. Comentarios a la Sentencia C-370 del 2006 y los procesos de Justicia y Paz
}

Daniel Florez Muñoz ${ }^{1}$

\section{INTRODUCCIÓN}

Dentro de una de las tradiciones jurídicas mas criticas el derecho se nos muestra como "el producto de la dinámica política y social que lejos de ser ajeno a las tensiones de dicha dinámica las reproduce."(Kennedy, 1999). Pero aún siendo más consecuentes con una tradición que sin caer al formalismo es más creyente en las posibilidades de resistencia que se puedan hacer desde el derecho a los abusos políticos y ante las desigualdades sociales, así como la apelación la relativa autonomía jurídica y a su racionalidad a la hora de contemplar las herramientas y posibilidades de controvertir el actual estado de cosas vigentes e iniciar la construcción de un mundo más libre y equitativo.

Ambas posiciones (la primera como los CLS y la segunda como las tesis del llamado Pluralismo Jurídico o las de Derecho y Desarrollo), de formas mas o menos criticas reconocen la vinculación que existe en las transformaciones jurídicas y los cambios económicos, políticos y sociales, pero al ser la segunda abiertamente constructivista se ve en la obligación de proponer formas alternas a las vigentes para alcanzar en mayor grado la materialidad de mínimos de justicia en las decisiones judiciales y de hacer encajar o amoldar las pretensiones o fines del derecho en la realidad material de los asociados a los estados, esta nueva corriente ha sido bastante influyente en el desarrollo del constitucionalismo latinoamericano actual, y es desde esas ideas del también denominadas "nuevo derecho", desde donde se podría comenzar ahora a pensar formas alternas de construcción de libertad, justicia e igualdad. Es por esto que el presente trabajo busca mostrar como desde un Estado Social de Derecho siendo este entendido como expresión de un momento histórico determinado, y siendo fiel a su filosofía y principios. No es posible para poner fin a los problemas de violencia y la barbarie históricamente recurrente, la construcción de modelos mas que "reconciliatorios" de tipo "pactista" en virtud de la desvinculación de la sociedad civil de los procesos en cuestión y el claro deterioro institucional, teniendo en cuenta también su abierta posición unilateral y sobre todo omitiendo las garantías minimamente reconocidas en los procesos de Justicia Transicional (en adelante Jtr) y el derecho Internacional.

En este entendido los procesos adelantados por la actual administración nacional, con miras a fomentar el desarme y el cese de las actividades bélicas; busca de esta forma absolutizar la

${ }^{1}$ Estudiante de de Derecho en la Universidad de Cartagena; Coordinador del Grupo de Investigación de de "Filosofia del Derecho, Derecho Internacional y Problemas Juridicos Contemporáneos"; Coordinador del Grupo de Investigación de "Filosafía del Derecho y Derecho Constitucional"; Miembro del Grupo de Investigación de "Sociología Jurídico-Penal y Anólisis Socio-Politico de los Procesos de Criminalización". Ha sido ponente en diversos Congresos Nacionales e Internacionales de Filosofia del Derecho, Filosofía Política y Derecho Constitucional. daniel.florez@hotmail.es 
soberanía estatal a partir de su aparato militar garantizando la prevalencia y autonomía del Estado, en la realidad estos parecen ser ideales cada ves mas lejanos.

Pero aun con la venia de los medios de masas, que muestran como realizada aquella fantasía Kantiana de "vivir en el mejor de los mundos posibles", esta aprobación consensualmente viciada por una global acción estratégica con respecto a fines sostenida por un cúmulo sistemático de falacias y distorsiones dolosas de la realidad, características propias de la realidad mediática en la medida que esta juega como elemento mas de la Industria Cultural, por lo tanto el consentimiento de las masas a las políticas implementadas por la administración, por estar viciado por la irracionalidad no puede liberar a las instituciones que un día surgieron con el compromiso de ser las garantes de los principios y valores constitucionales, olvidar o traicionar aquello contra lo que surgieron justificándose en un alto índice de popularidad. Los jueces como garantes del sano desarrollo político no le pueden hacer el juego al clientelismo.

La Corte Constitucional, es en este entendido, la portadora de la responsabilidad histórica que consiste en evitar a toda costa que se repita lo sucedido, en la Europa de los años 30 , su misión es precisamente garantizar la supremacía de aquella Carta Fundamental, denominada Constitución Política, la cual se sitúa dentro de ese nivel que debe entenderse entre otras cosas como las estrategias prácticas de poder, bien sea bajo la forma enunciativa de "suma de factores reales de poder" o como movidas por las "decisiones políticas del titular del poder constituyente". Ambas consideraciones (que son las más frecuentes) se tocan en un punto, y es el que la constitución solo es "real" si es expresión de una determinada situación fáctica que la ha motivado, por tanto le es previa y la llena de contenido, al tiempo quiero decir que la Constitución es necesariamente histórica, atendiendo igualmente al hecho de que la sociedad es la expresión de su desarrollo interno donde las dinámicas sociales, económicas y políticas marcan las pautas, la constitución es el reflejo y sobretodo el marco dentro del que se debe mantener dicha evolución social, político y económica. Y por esta razón la Carta Magna no puede ser entendida a partir del ahistoricismo racionalista del pensamiento normativo. No podemos olvidar que al ser la Constitución Política una forma de "racionalizar el ejercicio del poder, y de establecer cierta normatividad en la vida social", son el poder y la sociedad las que permiten el surgimiento de la misma y no viceversa (Ulff Olaph, 1983) en este entendido, la Corte Constitucional, no puede utilizar como referente una situación fáctica o una situación jurídica únicamente, si no que debe procurar apelar por un tercer referente que es la historia y a partir de este trípode la construcción deliberada de la realidad jurídico-política. Es tarea de la Corte Constitucional por tanto la construcción de un diálogo entre la realidad material y los principios y valores consagrados por el constituyente en su momento, es decir de la situación actual, y lo que simboliza la Constitución como un logro que significaría el fin de un periodo de la historia y la promesa de un no retorno. Naturalmente al ser este un órgano sin aparente control discrecional, solo nos queda esperar un fallo garantizado más por un criterio ético que por un criterio de tipo pragmático.

En virtud de lo limitado de la ponencia, tratare de analizar primeramente el concepto de Jtr, para entonces entender si la Ley 975 del 2005 llena mínimamente las expectativas y garantías que un proceso de esta naturaleza y seriedad debe tener, así como también enunciaremos varios procesos de cierta forma análogos a los propuestos por esta ley en Colombia a través de su historia, de igual forma brevemente analizaremos la concordancia de la C-370/2006 con los postulados del Estado Social de Derecho desarrollados en la paradigmática sentencia T-406/92 y naturalmente tratar de entender que pudo mover los argumentos de la Corte Constitucional y las implicaciones de cada uno. A modo de conclusión anticipada recalcaría la imperiosa necesidad de darle la voz a las víctimas sometiendo dicho concepto a revisión, y fomentar entre ellas (víctimas de Estado, paramilitares y de la guerrilla) posibilidades de diálogo y cooperación y sobre este supuesto comenzar a construir desde una justicia transicional 
y una justicia retributiva un nuevo escenario de participación democrática y pluralista y sobre todo garantizar la no repetición de los actos atrozmente realizados.

\section{ACERCADE LAJUSTICIA TRANSICIONAL}

No existe un concepto unificado acerca de Jtr. así como tampoco en su genealogía y evolución, pero una aproximación teórica a este cúmulo de prácticas instituciones y actores que conforman dichos procesos debe tomar como referencia siempre, tanto el derecho internacional como los procesos y garantlas internas o locales como lo son un estado previo de inseguridad y vulneración de derechos y un estado a alcanzar en el cual se pretenda superada dicha situación irregular, asi como una tensión entre derechos que unen uno y otro momento, la tensión entre la paz y los derechos de las victimas. En este orden de ideas, la justicia transicional hace referencia a un campo de actividad e indagación que centra la atención en cómo las sociedades ubicadas en un legado después de abusos de los derechos humanos, atrocidades a masas $u$ otras formas de trauma social severo, incluyendo el genocidio o guerra civil se organizaban para construir un futuro más democrático, equitativo, o tranquilo. El concepto es comúnmente comprendido como un armazón para confrontar los abusos pasados como un componente para la mayor transformación política.

Esto generalmente implica una combinación complementania entre una estrategia jurídica y extrajuridica, como perpetradores acusantes: estableciendo comisión de verdad y otras formas de investigación acerca del pasado; labrando esfuerzos hacia la conciliación al interior de las sociedades fracturadas. Instaurando medidas para la mayoría afectada por la violencia o el abuso, perpetuando y recordando a las victimas y reformando un amplio espectro de instituciones estatales ofensivas (policía o fuerzas armadas) con miras a tratar de impedir violaciones futuras.

La justicia transicional dibuja sobre dos fuentes primarias la construcción de un argumento nomativo que permita confrontar el pasado (asumiendo las condiciones locales damos soporte al proceder). Primer, el movimiento de los derechos humanos ha permitido un desarrollo en el campo, y la construcción de una auto-conciencia victimacéntrica. Los practicantes de la justicia transicional se inclinan a perseguir estrategias que permitan la consistencia de los derechos y las victimas, los sobrevivientes y los familiares de las primeras. Una fuente de legitimidad adicional se deriva de los derechos humanos y la Legislación Humanitaria (The Encyclopedia...., 2004) de la anterior idea se desprenden los elementos claves de la denominada JTr que son: La Justicia, La Verdad, La Reparación, La Reconciliación, Las reformas Institucionales.

Teitel, realizó una genealogía de la JTr y consideró la existencia de tres distintos momentos históricos: el periodo de la segunda posguerra, caracterizado por reconocer en el castigo de los violadores de derechos humanos un valor universal y exigible sin restricciones; el periodo posterior a la guerra fría, que hubo en cambio de confrontar la tensión entre las exigencias jurídicas de justicia y las necesidades políticas de paz; y la época actual, que demuestra una tendencia hacia la nomalización de la justicia transicional y, en concreto, hacia el empleo del lenguaje del derecho de la guerra en contextos de paz, tal y como sucede en el caso del terrorismo (Teitel, 2003). Naturalmente dicha categorización no implica que un acto desarrollado posterior al cambio de modelo de justicia transicional no corresponde a uno previo, simplemente marca una linea de evolución general del concepto. 


\section{AMNISTIAS E INDULTOS EN COLOMBIA}

PERIODO PRESIDENCIAL

Belisario Betancur (1982-1986)

Virgilio Barco

(1986-1990)

César Gaviria (1990-1994)

Ernesto Samper

(1994-1998)

Andrés Pastrana

(1998-2002)

Álvaro Uribe

(2002-i?)

\section{NORMA}

Ley 35 de 1982

Ley 49 de 1985

Ley 77 de 1989

Decreto 206 de 1990

Decreto 213 de 1991

Decreto 1943 de 1991

Ley 104 de 1993

Ley 241 de 1995

Ley 418 de 1999

Ley 782 de 2002

Decreto 128 de 2003
Indulto, cesación de procedimiento, auto inhibitorio por delitos políticos o conexos.

Indulto, cesación de procedimiento, auto inhibitorio por delitos políticos o conexos. Cobijó el acuerdo de paz con el M-19.

Extinción de la pena y de la acción penal por delitos políticos o conexos. Cobijó los acuerdos de paz firmados con el PRT, con el EPL y con el MAQL.

Indulto y amnistía. Cobijó el acuerdo de paz firmado con los Comandos Ernesto Rojas del 20 de marzo de 1992.

Indulto, cesación de procedimiento, la resolución de preclusión de la instrucción o la resolución inhibitoria. Cobijó los acuerdos de paz firmados en 1994 con la CRS, las Milicias Urbanas de Medellín y el Frente Francisco Garnica de la Coordinadora Guerrillera.

Prorroga y modifica la Ley 104 de 1993. Abrió la posibilidad de otorgar beneficios jurídicos a los grupos de autodefensa previo abandono voluntario de la organización y la entrega a las autoridades.

Extinción de la pena y de acción penal por delitos políticos y conexos.

Indulto por delitos políticos o conexos y favor de quienes abandonen voluntariamente sus actividades como miembros de grupos armados al margen de la ley. Cesación de procedimiento, resolución inhibitoria $y$ resolución de preclusión por delitos políticos o conexos.

(Fundación Social, 2005) 
ANÁIISIS DE IAA

SENTENCIA C-370

DEL 2006

La sentencia C- 370 - 06 procedió a analizar si la Ley 975 de 2005 cumplía los requisitos formales exigidos para su existencia, es decir, si se expidió de conformidad con el trámite establecido en la Constitución para las leyes de este tipo; al igual que si en realidad se trata de una ley mediante la cual ol Congreso de la República decretó sin decirlo un indulto o una amnistia y por último en consecuencia, esa ley debla haber sido expedida con sujeción a las formalidades propias de las leyes de esta especie; al igual que si los articulos $70 \mathrm{y}$ 71 de la ley en cuestión cumplieron o no con las formalidades exigidas en la Constitución para hacer parte de una ley de la República.

\section{CONTROLFORMAL DELALEY 975 - 2005}

No toda regulación legal de los derechos fundamentales tiene naturaleza de ley estatutaria, sino sólo aquella que de alguna manera toca su núcleo esencial. (...) la regulación del procedimiento penal no tiene reserva de ley estatutaria, como tampoco la tipificación de los delitos ni el establecimiento de sanciones. La Ley 975 de 2005 no crea una jurisdicción especial, sino que simplemente atribuye a la jurisdicción ordinaria un procedimiento especial que debe surtirse ante la Fiscalía General y los tribunales superiores, de manera que no se afecta la estructura general de la administración de justicia, ni se tocan principios generales 0 aspectos sustanciales de la Rama Judicial del poder público, razón por la cual tampoco por este aspecto debia ser objeto de una ley estatutaria.

\section{INDULTO OAMNISTIA, LAINCIERTA NATURALEZA PENALLEY 975- 2005}

Frente a este punto la Corte establece que no hay ni indulto ni amnistía "Como en la ley no se dispone la extinción de la acción penal en relación con los delitos que puedan ser imputados a miembros de grupos armados que decidan acogerse a aquella, no se puede decir que esta ley dicta amnistia". En opinión del Profesor Alfonso Gómez Méndez existe una clara amnistía disfrazada para evitar la responsabilidad intemacional que este tipo de procesos exige así como los controles y seguimientos propios de estos procesos.

\section{EN RELACIONALOSARTÍCULOS 70 Y 71 DELA LEY 975-2005}

"Puesto que en los debates realizados en el congreso a raíz del proyecto de ley 293 de 2005 Cámara y 211 de 2005 Senado los artículos 61 y 64 acusados son inexequibles por vicios de procedimiento en su formación al no estar acorde con el articulo 158 de la constitución politica."

Una vez terminado el análisis de la sentencia, donde se deja claro que la ley de verdad justicia y reparación no está hecha para conceder indultos o amnistia me pegunto ¿cuáles son los antecedentes que dieron como resultado que el gobiemo insertara los art. 70 y 71 de la presente ley que hoy son declarados inexequibles?

Atendiendo a lo manifestado por el gobierno la Ley 975 está hecha para conquistar una salida pronta al conflicto que busque garantizar la reconciliación nacional. En el marco de la desmovilización de los grupos paramilitares que tiene como antecedente La ley $782^{2}$ de 2002 que establece el marco para las negociaciones con los grupos al margen de la ley, así:

El Artículo 19: El Gobiemo Nacional podrá conceder, en cada caso particular, el beneficio de indulto a los nacionales que hubieren sido condenados mediante sentencia ejecutoriada, por hechos constitutivos de delito político cuando a su juicio, el grupo armado organizado al margen de la ley con el que se adelante un proceso de paz, del cual forme parte el solicitante, haya demostrado su voluntad de reincorporarse a la vida civil.

2Esta ley reforma la leyes 418 de 1997 y 548 de 1999. 
Es en el marco de esta ley donde se articula la necesidad de recocer el estatus político a las autodefensas puesto que ellas entran en plano de adelantar procesos de paz con el gobierno; a partir de aquí se trataría de reglamentarla a través de los Decretos 128 y 3360 de 2003, en el cual el gobierno establece lo siguiente:

1) Decreto 128 del 22 de enero de 2003: establece los mecanismos para acceder a los beneficios de la desmovilización. el Art. 12; funciones del CODA: N\#5 Tramitar las solicitudes de aplazamiento o suspensión de la ejecución de la pena e indulto ante los jueces de ejecución de penas y los Ministerios del Interior y de Justicia y el Derecho.

2) Decreto 3360 del 21 de noviembre de 2003: art.1: Cuando se trate de desmovilización colectiva en el marco de acuerdos con el Gobierno Nacional, la calidad de miembro del grupo armado organizado al margen de la ley de que se trate, se acreditará mediante una lista de desmovilizados suscrita por los voceros 0 miembros representantes de dicho grupo, en la que se reconozca expresamente tal calidad. (...). La lista de que trata el presente artículo habilita al desmovilizado para acceder al proceso de reincorporación y sustituye, para todos los efectos, la certificación expedida por el Comité Operativo para la Dejación de las Armas, CODA. A partir de la ley 975 de junio 25 de $2005^{3}$ que tiene por objeto según el artículo 1:

“acilitar los procesos de paz y la reincorporación individual o colectiva a la vida civil de miembros de grupos armados al margen de la ley" (...).Se entiende por grupo armado organizado al margen de la ley, el grupo de guerrilla o de autodefensas, 0 una parte significativa e integral de los mismos como bloques, frentes u otras modalidades de esas mismas organizaciones, de las que trate la Ley 782 de 2002.

El Artículo 71 que eliminaba toda concepción histórica de lo que es el delito político añade:
Sedición. Adiciónese al artículo 468 del Código Penal un inciso del siguiente tenor: "También incurrirá en el delito de sedición quienes conformen o hagan parte de grupos guerrilleros 0 de autodefensa cuyo accionar interfiera con el normal funcionamiento del orden constitucional y legal. En este caso, la pena será la misma prevista para el delito de rebelión

Ahora bien, vistos los antecedentes y la materia que revisa la Corte Constitucional, el fallo de la sentencia C-370/2006 parte del hecho que la Ley 975 se debía armonizar con los criterios formados por el Tribunal de san José. La sentencia busca un concepto de reparación de víctimas en relación causa-efecto entre el daño colectivo causado y las personas individualizadas frente a la ley, noto que es un punto discutible puesto que no existe la posibilidad de determinar objetivamente los daños causados a determinada comunidad.

En este fallo la Corte se aleja de la jurisprudencia internacional de la Corte Penal Internacional y acomoda un concepto de justicia por fuera del Estado Social de Derecho respondiendo a los intereses de la política de turno y se comete con ello la autofagia de dar validez a los criterios formales de reparación y no buscar la reparación en un sentido material alejándose de uno de los principios básicos del Estado Social de Derecho que no es más que la materialización de la justicia. Al renunciar a la memoria como requisito fundate del proceso, no podrá nunca haber reparación material ni mucho menos reconciliación.

Por otra parte como bien lo muestra el profesor Rodrigo Uprimny (Uprimny, 2006) La jurisprudencia internacional (Corte Interamericana de Derechos Humanos) y doctrina internacional (informe de derechos humanos $\mathrm{ONU}$ ), reconocen que el Derecho a la Justicia de las víctimas, está compuesto por dos derechos fundamentales sin los cuales no podría haber justicia, estos son el Derecho a la Reparación y el derecho a la Verdad que consiste en "conocer las circunstancia

\footnotetext{
${ }^{3}$ Por la cual se dictan disposiciones para la reincorporación de miembros de grupos armados organizados al margen de la ley, que contribuyan de manera efectiva a la consecución de la paz nacional y se dictan otras disposiciones para acuerdos humanitarios.
} 
de modo, tiempo y lugar en las que los crímenes atroces que las afectaron ocurnieron as! como las razones por las cuales ello fue asi". En relación a esto la Ley de Justicia y Paz aboga por una verdad esencialmente judicial y no estableció mecanismos extrajudiciales institucionalizados para esclarecer la verdad del fenómeno del paramilitarismo. La ley 975 aboga por una confesión como diría el ya citado profesor miembro de Dejusticia, Rodrigo Uprimny una "confesión tipo Buffet" en la cual el desmovilizado si quiere acogerse a los beneficios de la ley, NO está obligado a declarar todos sus delitos en su version libre aunque sí a declararse culpable de los que le imputa la Fiscalia, de esta forma, si más adelante se le comprueban más delitos de los imputados y de los declarados, este puede reconocerlos y de esta forma también se les incluirán en el beneficio punitivo es decir una pena alternativa que nunca serán penas superiores a ocho años. De allí la metáfora del Buffet en los que el sindicado se acoge a un máximo de prisión y va reconociendo los delitos, poco a poco, conforme se los van descubriendo. Lo cual desdibuja completamente la seriedad que debería acompañar un proceso de esta naturaleza. El Comisionado de Paz, en una flagrante muestra de ignorancia jurídica, dice que esto debe ser asi porque de lo contrario se le estaría violando el derecho fundamental a la no auto-incriminación, lo cual es completamente desacertado ya que dicho derecho no excluye que el Estado pueda ofrecer algún beneficio por confesar un delito siempre y dicha confesión la haga la persona de una forma libre y espontánea, igualmente el juez tendrá la obligación de proteger este derecho vulnerado siempre que el acto de la confesión sea realizado no de manera libre, espontánea y consiente. Por lo tanto el debate acerca de la negociación de las penas y el reconocimiento de los delitos ya se encuentra superado por la doctrina y jurisprudencia constitucional.

Aparte de esto, gracias a la ley en cuestión la Fiscalia cuenta con un tiempo muy limitado para la investigación de los delitos presuntamente cometidos por los desmovilizados, se dejan vacíos en cuanto al problema de la expropiación de tierras, la ubicación de fosas comunes y las actividades de los patrones de los mismos. El derecho a la verdad se ve violado completamente. No es posible hablar de verdad donde una ley propone de forma contradictoria que el desmovilizado confiese pero que no seauto incrimine, es decir lo que la ley busca no es mas que el sindicado reconozca ser miembro de un grupo de autodefensas y aceptar lo que la Fiscalla le diga. Si hace esto se acogerá a los tan especiales beneficios de la Ley de Justicia y Paz. Pero al final de todo este proceso, ¿quién le dice a los familiares donde están sus muertos y por qué y cómo murieron?

Solo realizando este breve análisis, de uno de los puntos de la Ley 975 del 2005 vemos como la Corte Constitucional ha debido declararla inexequible en virtud de los cortos términos de que dispone la Fiscalia para investigar el delito, esto según el artlculo 250 de la Constitución Política que estipula que es función de la Fiscalía la investigación COMPLETA de TODOS los hechos, por lo tanto la inexequibilidad sería motivada por la no adecuación de las exigencias de los plazos de investigación y juzgamiento sean razonables y suficientes. La razonabilidad de un plazo se encuentra sujeta al núcleo esencial del derecho fundamental del debido proceso y, en esa medida, puede verse vulnerada tanto por su excesiva amplitud, como por su desmesurada estrechez. Según la Corte Constitucional, la razonabilidad de un plazo debe analizarse entonces en función de la naturaleza del delito, de su grado de complejidad, del número de sindicados y de los efectos sociales del mismo.

\section{CONCLUSIONES}

La Ley de Justicia y Paz tal como quedó después de la sentencia C- 370 del 2006, a pesar de las concretas modificaciones derivadas de la modulación del fallo por parte de la Corte Constitucional sigue siendo una flagrante muestra del desconocimiento de los principios básicos del Estado Social de Derecho, de la jurisprudencia constitucional y de la doctrina internacional, aun cuando para pocos no es sorpresa este tipo de prácticas por parte de la administración nacional 
actual, si lo es por parte de la Corte Constitucional, en la medida en que los jueces hoy deberían poder ser los salvavidas de las democracias liberales que tantas patologías han mostrado en su desarrollo, esta es la función política del poder judicial, garantizar el respeto y materialización de los derechos de los más desfavorecidos y evitar las prácticas totalitarias y abiertamente antijurídicas de los gobiernos populistas de turno. Esto es posible, siempre y cuando podamos contar con fallos basados en criterios académicos y sobretodo éticos, y no de simples criterios de tipo pragmáticos y acomodaticios. Este fallo puede resumirse en el nuevo principio jurídico que muestra como antes de judicializar la política como forma de control y balance del poder publico, se politizó la justicia quedando para algunos la más alta corte del país en el bolsillo del carismático y mesiánico líder, este nuevo principio jurídico no es otro a: DAME LAS ENCUESTAS Y TE DARÉ EL DERECHO.

\section{BIBLIOGRAF'́A}

- C - 370 DEL 2006. Magistrado ponente: Dr. MANUEL JOSÉ CEPEDA ESPINOSA Dr. JAIME CÓRDOBA TRIVIÑO Dr. RODRIGO ESCOBAR GIL Dr. MARCO GERARDO MONR OY CABRA Dr. ÁLVARO TAFUR GALVIS Dra. CLARAINÉS VARGAS HERNÁNDEZ

- KENNEDY, DUNCAN. (1999) Libertad y Restricción en la Decisión Judicial, siglo de Hombres Editores, Universidad de losAndes

- LEY975DEL2005

- LEY 293 DEL2005

- LOPEZM, DIEGO. (2008), El Derecho de los Jueces. LEGIS

- MERCADO, DAVID. (2008) Manual de Teoría Constitucional. Rodríguez Quito Editores.

- ULFF, OLAPH. (1983) Que es el Constitucionalismo?

- UPRIMY, Rodrigo (Coord.) ¿Justicia transcional sin transcision?. Manuscrito sin corregir del libro del mismo titulo que fue publicado por DJS en Enero de 2006.

- T-406 DE 1992. Magistrado Ponente: Dr. CIRO ANGARITABARON

- TEITEL, R(2003) "Transitional Justice Genealogy", Harvard Human Rights Journal, No. 16, pp. 69-94.

- The Encyclopedia of Genocide and Crimes Against (2004). Humanity (Macmillan Reference USA,), vol. 3, pp. 1045-1047. 